\title{
Cost and Indications of Blood Transfusions in Pediatric Oncology in an African Hospital
}

\author{
John Recardie Murray and D. Cristina Stefan*
}

Department of Paediatrics and Child Health, Tygerberg Hospital and Stellenbosch University, Tygerberg, Cape Town, South Africa

\begin{abstract}
Background: Red blood cells and platelet concentrates are frequently used in paediatric oncology. There is little literature on the indications and costs of this adjuvant therapy.

Aim: To retrospectively evaluate the indications, amounts and costs of transfusing blood products in 2008 in the Department of Paediatric Oncology at Tygerberg Children's Hospital, Cape Town.

Material and Method: The patient records were analyzed for age, sex, disease and stage, indications for transfusion and type of blood product as well as amount. The costs were obtained from the Blood Bank for each item released for every patient.

Results: Thirty-nine children with cancer were transfused, between one unit and 34 units of blood products per patient, during their treatment in 2008. The total cost of this therapy in 2008 was ZAR 941,966 = USD 125,595 = EUR 89,711. The maximum cost per patient amounted to ZAR 70,682 = USD 9,424 = EUR 6,731 and the minimum ZAR $914=$ USD $121=$ EUR 87. The average expenditure per patient was ZAR 24,125 = USD 3,216 = EUR 2,297. The management of leukemia required the highest usage of blood products per patient.

Conclusion: The use of blood products is indispensable during the treatment of numerous haematology - oncology diseases. Their indications should be specified in internal protocols and their actual use should be audited frequently due to the considerable costs.
\end{abstract}

Keywords: Blood transfusions, indications, cost, African hospital.

\section{INTRODUCTION}

Transfusion with blood products is essential therapy for many serious diseases $[1,2]$. In haematology and oncology the use of blood products is crucial in the management of leukaemia, aplastic anaemia, haemophilia and many other conditions.

Donated blood requires extensive processing and testing before being transfused. A unit of blood is therefore both expensive and a limited resource world wide, however South Africa is self-sufficient in blood products. Blood transfusions and services rendering them are regulated under international standards by the South Africa's Human Tissue Act 65 of 1983 and by regulations issued by the Minister of National Health and Population Development. There are two nonprofit independent services in South Africa, the Western Province Blood Transfusion Service (WPBTS) and South African National Blood Service (SANBS).

Clinical transfusion guidelines for paediatrics are limited and vary in their application [3-8]. Guidelines in children are different from those in adults, because of growth and

*Address correspondence to this author at the PO Box 19063, Department of Paediatrics and Child Health, Tygerberg Hospital and Stellenbosch University, Tygerberg, Cape Town 7550 South Africa; Tel: +27 21 9389404;

Fax: + 2721 9389138; E-mail: cs@sun.ac.za development that must be taken into consideration. With the limited data available on the indications, safety and effect on outcome of blood transfusions in paediatrics, it remains difficult to establish a universal transfusion guideline. With variations between different centres, many physicians deviate from established guidelines. There are no controlled trials upon which to base decisions about blood products transfusions in this age group. The decision therefore depends on clinical judgment, taking into account the child's general condition, the presence or absence of bleeding and whether or not there are signs of hematological recovery [7].

Blood products can contribute significantly to the costs of a medical facility, especially in haematology and oncology, where they are frequently used [8-10]. There is no data available on the cost and indications of blood transfusions in paediatric oncology in a third world country. On a continent where gross domestic product figures per capita, excepting South Africa, rarely exceed $2000 \$$, and in many countries in fact are less than $1000 \$$, the expenditure incurred by the use of blood products in children may be unaffordable.

This study proposes to evaluate the indications of blood transfusions, estimate the costs of blood transfusions, and look at the spectrum of diseases and products transfused in an African Paediatric Oncology Unit over one year. 


\section{METHODS}

The study was conducted in the Department of Paediatric Oncology, Tygerberg Children's Hospital in Cape Town, South Africa. The patient records were analyzed retrospectively for age, sex, disease and stage, indication and type of blood product transfused. Costs were obtained from the WPBTS for each item released for every patient. The study population included all paediatric oncology patients (birth to 17 years old) who received a blood product in the Oncology Unit, in the year 2008.

All patients who presented at our hematology oncology unit which serves a large area in Western Cape were included. The unit is governmental and all patients have free access. The large majority of the patients have a low socioeconomic status with an average income of less than R36,000 $(\$ 4,860)$ per year/ single person or R50 000 $(\$ 6,750)$ per year / family income.

Exclusion criteria were adults (18 years and older), no oncology disease, transfused outside Oncology Unit and Haemophilia. Blood products included in the study were divided into seven groups. Data were then processed and transferred to an Excel spreadsheet to be analyzed by specific statistical methods.

Our pediatric hematology oncology unit at Tygerberg Children's Hospital in Cape Town has a set of transfusion guidelines. Those guidelines are in most cases followed by the physicians, exceptions are permitted and the guidelines in few occasions were adapted to the needs of the patients. Prophylactic platelets transfusions were not used.

The currency used was the South African Rand (ZAR). Conversions to United States Dollar (USD) and Euro (EUR) were made at the existing rate at the time of writing.

\section{RESULTS}

Forty-two children with cancer were transfused, between one and 34 units of blood products per patient, during their treatment in 2008 (Table 1). A total of 450 units were transfused. The most common product used was adult leukocyte depleted red cell concentrate. More pooled random donor platelets were used compared to single donor aphaeresis mega units. The haemoglobin value ranged from 3.6 to $9.2 \mathrm{~g} / \mathrm{dl}$ for red cell concentrate (RCC) and platelet count from 3 to $50 \times 10^{9} / \mathrm{L}$ for platelet transfusions. Fresh frozen plasma was used infrequently.

The total cost of this therapy in 2008 was ZAR 941,966= USD 125,595 = EUR 89,711 Table 2. The maximum cost per patient amounted to ZAR 70,682 = USD 9,424 = EUR 6,731 and the minimum ZAR $914=$ USD $121=$ EUR 87. The average expenditure per patient was ZAR 24,125 = USD $3,216=$ EUR 2,297. Acute Lymphocytic Leukaemia (ALL) accounted for the most products transfused, with the highest cost over all.

The protocol used for the treatment of leukemia was the German BFM 2004. The total cots of treatment of ALL is around R 500,000 (\$68,000). Most common complications seen were viral infections, followed by bacterial infections, febrile neutropenia and mucositis. The cost of antibiotic therapy was not collected. The total days spent in hospital varied between few days to few weeks. Children of families with poor socioeconomic circumstances and who live far from the hospital were accommodated in special facilities.

Table 1. Baseline Characteristics

\begin{tabular}{|l|l|}
\hline Number of patients & \multicolumn{1}{|l|}{} \\
\hline Age & $\mathbf{4 m - 1 7 y}$ \\
\hline Range & $\mathbf{7 y 4 m}$ \\
\hline Mean & \multicolumn{2}{|l|}{} \\
\hline Sex & $\mathbf{2 0}(\mathbf{4 8})$ \\
\hline Female (\%) & $\mathbf{2 2}(\mathbf{5 2})$ \\
\hline Male (\%) & \multicolumn{1}{|l}{} \\
\hline Units transfused per patient & $\mathbf{1 - 3 4}$ \\
\hline Range & $\mathbf{1 1}$ \\
\hline Mean & \multicolumn{1}{|l}{} \\
\hline Transfusions per patient & $\mathbf{8 . 4}$ \\
\hline Range &
\end{tabular}

The management of osteosarcoma required the highest usage of blood products per patient, but the highest cost per patient was registered in a case of chronic myeloid leukaemia in a blast crisis (CML). This was due to the use of more expensive single donor apheresis units in CML, while less costly random donor pooled platelets were used in the osteosarcomas. Nephroblastoma and aplastic anaemia had high costs per patient, but relative low number of units per patient. This was due to the usage of more platelets compared to the less expensive RCC. Among the leukaemias, CML with blast transformation was the most expensive per patient, followed by acute myeloid leukaemia, with acute lymphatic leukaemia at half the cost.

Table 2. Products Transfused

\begin{tabular}{|l|l|l|}
\hline & Units & Costs \\
\hline \hline Red Cells Concentrates & $\mathbf{2 1 3}$ & $\mathbf{R ~ 2 4 9 , 8 1 1}$ \\
\hline Platelets Pooled & $\mathbf{8 3}$ & $\mathbf{R ~ 3 0 9 , 7 0 2}$ \\
\hline Platelets Mega Units & $\mathbf{7 0}$ & $\mathbf{R ~ 3 1 2 , 8 6 0}$ \\
\hline Platelets Pediatrics & $\mathbf{4 7}$ & $\mathbf{R ~ 4 2 , 6 8 6}$ \\
\hline Red Blood Cells Pediatrics & $\mathbf{2 7}$ & $\mathbf{R ~ 2 0 , 7 4 1}$ \\
\hline Fresh Frozen Plasma & $\mathbf{9}$ & $\mathbf{R ~ 5 , 8 5 0}$ \\
\hline Fresh Frozen Plasma Pediatrics & $\mathbf{1}$ & $\mathbf{R ~ 3 1 6}$ \\
\hline Total & $\mathbf{4 5 0}$ & $\mathbf{R ~ 9 4 1 , 9 6 6}$ \\
\hline
\end{tabular}

The most common indication for RCC transfusion was haemoglobin less then $8 \mathrm{~g} / \mathrm{dL}$, with high risk for development of symptomatic anaemia with no other medical therapy likely to correct the anaemia. This indication was followed by symptomatic anaemia. The most common indication for 
platelets was a count of less then $50 \times 10^{9} / \mathrm{L}$ with active bleeding or before surgical procedure. This was followed by a platelet count of less then $10 \times 10^{9} / \mathrm{L}$.

\section{DISCUSSION}

The use of blood products is indispensable during the treatment of numerous haematology and oncology diseases. Medical units are under increasing financial pressure and it is clear that blood products contribute significantly to the expenditure of a paediatric oncology unit. In this study we excluded other additional costs like pre-transfusion testing, some product preparation fees, infusion costs, intravenous lines, blood filters, adverse reaction management, labour, extra charges for blood bank, including after hour and cancellation fees. Previous studies showed that these extra costs would add significantly to the total costs of transfusing blood products [9-11]. The transfusions for haemophilia patients were not included. There are also noteworthy differences in the cost of units between the two blood transfusing services in South Africa. A unit RCC cost for example ZAR $749=$ USD $99=$ EUR 71 from the WPBTS and ZAR $1128=$ USD $150=$ EUR 107 from SANBS [12, 13].

The two organizations, the Western Province Blood Transfusion Service (WPBTS) and South African National Blood Service (SANBS) are two separate companies working independently with rates determined individually by their specific budgets, expenses, income, est.

As Tygerberg Hospital is located in Cape Town, units in this study were issued by the WPBTS. Further studies are needed to look at the full costs of transfusing blood products.

Platelet transfusions are not indicated in all causes of thrombocytopenia and may be contraindicated in certain conditions. Overall our guidelines were the same as first world counties, but compared to studies by Apelseth et al. [14], Cochrane Database Systemic Review 2004 [15] and Guidelines for the use of platelet transfusions in British Journal of Haematology [16], there were a few differences between transfusion services in developed and undeveloped countries. Single-donor apheresis platelet concentrates are used for the same indications, but due to higher costs and unavailability, pooled platelet concentrates may be used more frequently. Use of platelets prophylaxes were not given routinely, but platelet transfusions were given if count was less than $10,000 / \mathrm{uL}$ in bone marrow failure (due to disease, cytotoxic therapy or irradiation). Some guidelines uses a threshold of 5,000/uL for patients without any risk factors, but we generally used the higher value $[16,17]$. With active bleeding or before surgical procedure we used the same values, but before LP value of Pl $<30,000 / \mathrm{uL}$ was used in our hospital. Other challenges were unavailability of blood products, especially Single-donor apheresis platelet concentrates. The delay in blood results and issuing products were longer then compared with developed countries.

This is the first attempt to characterize financially the effort of fighting paediatric cancer in Africa using blood products. The final cost figure obtained as average per patient is definitely affordable in a resource-rich country; however, we believe that in many African countries it may be difficult to fund such therapy.
There are many challenges when establishing a universal transfusion guideline for paediatric oncology. The indications for blood transfusion are numerous, but vary between different centres. Guidelines use, for example, absolute values as an indication for a transfusion. This may be challenging as not all patients with haemoglobin under a certain value will benefit from a transfusion and someone that does not qualify, may benefit from it. In our review we felt that although some patients qualified for a transfusion, it was doubtful if they benefited from it. Further studies need to evaluate the appropriate transfusion level of haemoglobin that is age and disease specific, in correlation with the effect on outcome.

\section{CONCLUSIONS}

This is the first attempt at evaluating the costs and patterns of transfusion usage in paediatric oncology in an African country.

With the ever increasing financial pressure and limited resources, we need to critically review our practice and draw strict guidelines in order to optimize the use of blood products. Their indications should be specified in internal protocols and their actual use should be audited frequently due to the considerable costs. Reducing the inappropriate use of blood products will not only save money, but ease work load and decrease adverse effects. Alternative products like recombinant human erythropoietin and haemoglobin-based oxygen carriers need to be evaluated further. Erythropoietin appears to be cost-effective for reducing RBC transfusions in heterogeneous ICU populations, but needs to be evaluated further [18].

\section{ACKNOWLEDGEMENTS}

Dr. A. Bird, K. Smidt from Western Province Blood Transfusion Services; Prof. M. Kidd, Department of Statistics and Actuarial Sciences University of Stellenbosch.

\section{REFERENCES}

[1] Chang TT. Transfusion therapy in critically ill children. Pediatric Neonatol 2008; 49(2): 5-12.

[2] Desmet L, Lacroix J. Transfusion in pediatrics. Crit Care Clin 2004; 20: 229-311.

[3] Slonim AD, Joseph JG, Turenne WM, Sharangpani A, Luban NL. Blood transfusions in children: a multi-institutional analysis of practices and complications. Transfusion 2008; 48(1): 73-80.

[4] Roseff SD, Luban NL, Manno CS. Guidelines for assessing appropriateness of pediatric transfusion. Transfusion 2002;42: 1398-413.

[5] Clinical Guidelines for the use of Blood products in South Africa, $3^{\text {rd }}$ Edition. 2003 SANBS

[6] Ted Eastlund. Guidelines for transfusion therapy, $5^{\text {th }}$ Edition. October 2007.

[7] Transfusion Guidelines For Neonates and Older Children, British J Haematol 2004; 124(4): 433-453.

[8] Guidelines for the Blood Transfusion Services in the United Kingdom, 7th Edition. October 2005.

[9] Crémieux PY, Barrett B, Anderson K, Slavin MB. Cost of outpatient blood transfusion in cancer patients. J Clin Oncol 2000; 18(14): 2755-61.

[10] Agrawal S, Davidson N, Walker M, Gibson S, Lim C, Morgan CL, Cowell W. Assessing the total costs of blood delivery to hospital oncology and haematology patients. Curr Med Res Opin 2006; 22(10): 1903-9.

[11] Forbes JM, Anderson MD, Anderson GF, Bleecker GC, Rossi EC, Moss GS. Blood transfusion costs: a multicenter study. Transfusion 1991; 31(4): 318-23. 
[12] South African National Blood Service. State Patients Price List 2009. www.sanbs.org.za.

[13] Western Province Blood Transfusion Service. State Pricelist with effect from 01 April 2009. www.wpbtsmedical.org.za

[14] Apelseth TO, Bruserud O, Wentzel-Larsen T, Hervig T. Therapeutic efficacy of platelet transfusion in patients with acute leukemia: an evaluation of methods. Transfusion. 2010; 50(4): 766-75.

[15] Stanworth SJ, Hyde C, Heddle N, Rebulla P, Brunskill S, Murphy MF. Prophylactic platelet transfusion for haemorrhage after chemotherapy and stem cell transplantation. Cochrane Database Syst Rev 2004; (4): CD004269.
[16] Guidelines for the use of platelet transfusions. Br J Haematol 2003; 122(1): 10-23.

[17] Schiffer CA, Anderson KC, Bennett CL, et al. Platelet transfusion for patients with cancer: clinical practice guidelines of the American Society of Clinical Oncology. J Clin Oncol. 2001; 19(5): 1519-38.

[18] MacLaren R, Sullivan PW. Cost-effectiveness of recombinant human erythropoietin for reducing red blood cells transfusions in critically ill patients. Value Health 2005; 8(2): 105-16.

(C) Murray and Stefan; Licensee Bentham Open.

This is an open access article licensed under the terms of the Creative Commons Attribution Non-Commercial License (http://creativecommons.org/licenses/ by-nc/3.0/) which permits unrestricted, non-commercial use, distribution and reproduction in any medium, provided the work is properly cited. 